\title{
Alexandra Pion, Stendhal et l'érotisme romantique
}

\section{Michel Arrous}

\section{(Q) OpenEdition}

\section{Journals}

\section{Édition électronique}

URL : http://journals.openedition.org/studifrancesi/5663

DOI : 10.4000/studifrancesi.5663

ISSN : 2427-5856

\section{Éditeur}

Rosenberg \& Sellier

\section{Édition imprimée}

Date de publication : 1 septembre 2011

Pagination : 423-424

ISSN : 0039-2944

\section{Référence électronique}

Michel Arrous, «Alexandra Pion, Stendhal et l'érotisme romantique », Studi Francesi [En ligne], 164 (LV |

II) | 2011, mis en ligne le 30 novembre 2015, consulté le 08 janvier 2021. URL : http://

journals.openedition.org/studifrancesi/5663; DOI : https://doi.org/10.4000/studifrancesi.5663

Ce document a été généré automatiquement le 8 janvier 2021.

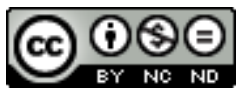

Studi Francesi è distribuita con Licenza Creative Commons Attribuzione - Non commerciale - Non opere derivate 4.0 Internazionale. 


\title{
Alexandra Pion, Stendhal et l'érotisme romantique
}

\author{
Michel Arrous
}

\section{RÉFÉRENCE}

ALEXANDRA PION, Stendhal et l'érotisme romantique, préface de Béatrice DIDIER, Presses

Universitaires de Rennes, 2010, $281 \mathrm{pp}$.

1 Adaptation d'une thèse consacrée aux processus constitutifs de l'érotisme stendhalien, cet ouvrage s'attache à en évaluer la portée philosophique, sociale et esthétique en le situant dans la pensée romantique. De l'Amour en est le centre, texte pivot dont les sources, érudites ou propres à la subjectivité de Stendhal, et les présupposés sensualistes, idéologiques et poétiques, sont sérieusement étudiés. Enfin, Alexandra Pion a voulu expliquer en quoi ce «témoignage essentiel de l'érotique romantique» annonçait les érotologues contemporains.

2 Les lectures que Stendhal a pour la plupart consignées dans la Filosofia nova font l'objet d'une convaincante analyse de l'imagination, de la cristallisation, et de la mélancolie érotico-sentimentale, fondement de l'amour-passion. On en trouvera un bel exemple dans la définition de l'amour comme expérience esthétique (chap. IV: «Imaginer, c'est aimer»), car si la sensibilité stendhalienne est réceptrice, elle est aussi créatrice. Il y a dans De l'Amour un double enjeu érotique et esthétique puisque, sans ce travail de l'imagination sensitive qu'est la cristallisation, sans esthétisation du désir, le sentiment érotique s'affaiblit. Chez Stendhal amour et désir finissent par se confondre.

3 La seconde partie s'ouvre sur l'expérience érotique de Stendhal dont la vie sentimentale et sexuelle est passée au crible: lectures voluptueuses, amours de garnison, basses aventures, femmes honnêtes et femmes équivoques, velléités nuptiales, etc... (on regrettera que le très fameux frontispice de Félicien Rops pour une réédition du $H B$ de Mérimée soit passé à la trappe). Cette revue de faits et gestes bien connus confirme que Beyle, préoccupé par la psychologie féminine et l'art de la 
séduction, oscilla longtemps entre Don Juan et Saint-Preux. Mais sa réputation de Lovelace suffirait-elle à expliquer le catastrophique "roman de Métilde»? A. Pion rappelle opportunément que si Stendhal a échoué dans sa quête romanesque d'un cœur tendre, ce n'est pas par incapacité à aimer, mais, sans doute - P. Laforgue l'a montré parce que l'amour ne pouvait avoir véritablement cours entre 1800 et 1830. L'Eros romantique, à la fois libertin et idéaliste, souffrait d'un problème social ou, pour reprendre l'excellente formule d'A. Pion, «le malaise érotique est un malaise social». On trouvera au chapitre V («Démoralisation érotique et babilanisme social») deux exemples de ce phénomène. Armance, étude d'un cas physiologique doublée d'une étude sociale, confirme la «dépression romantique». Le tempérament mélancolique prédispose à la défaillance érotique, mais l'impuissance est d'ordre social, l'impuissance physique renvoyant à l'impuissance sociale, ainsi que l'avait suggéré Francine MarillAlbérès. Suit logiquement le cas de Lamiel, autre forme de babilanisme qui se mue en une recherche effrénée du plaisir. Parmi les héroïnes stendhaliennes françaises Lamiel occupe d'ailleurs une place à part, ne serait-ce que parce qu'il lui sera donné de se défaire de sa frigidité (frigidité de Mme de Rênal, avant d'avoir connu Julien; frigidité de Mathilde victime de son bovarysme et de son narcissisme). L'étude du paradoxe de l'amour qui fait la nouveauté de Lamiel doit certes beaucoup à M. Crouzet et D. Philippot, mais A. Pion a su tirer parti de leurs analyses pour montrer comment Lamiel s'assume en tant que sujet érotique. Lamiel est bien un "roman d'apprentissage désabusé et douloureux» dont l'héroïne connaîtra finalement le véritable amour avec Valbayre. Ce personnage de femme naturelle, libre et vivante illustre les théories de $D e$ l'Amour. A. Pion, après E. Constans et R. Bolster, situe Stendhal dans le débat féministe sur l'amour en évoquant les positions de Tracy, Sénancour, Balzac, et même l'«anarchie sexuelle» de Fourier dont Stendhal est évidemment bien éloigné! Selon Stendhal, opposé à toute institutionnalisation de l'érotisme, seule la «vraie passion» peut légitimer l'union de deux êtres, aussi le féminisme des Idéologues ne peut-il le satisfaire. Bien qu'il ait proposé une réforme de l'éducation des filles, Tracy juge que l'amour ne doit être qu'une passion tiède, une «douce amitié» qui assure le développement harmonieux de la famille. Quant à Sénancour - réformateur que Stendhal n'a jamais mentionné mais qu'il a pu lire, comme Sénancour a pu lire Stendhal - son De l'Amour (1805, rééd. 1829 et 1834) offre bien des analogies, des «résonances» déjà relevées par B. Didier. Ce disciple affranchi de Tracy est lui aussi un moraliste qui n'envisage pas l'amour absolu car seule compte la famille. À la différence de celui de Stendhal, le féminisme de Sénancour est bien loin d'être évident. L'ars erotica balzacienne en est tout aussi éloignée: il s'agit là encore, cette fois sous l'influence de Bonald, d'un féminisme du mariage et de la famille. Stendhal porteparole d'un féminisme autre? De l'Amour ne cautionne pas le mariage et son auteur croit moins à l'amour qu'à l'amour-passion. Stendhal a toujours jugé le mariage incompatible avec l'amour (voir les lettres à Pauline): l'égotiste ne le conçoit que sous la forme d'une contrainte personnelle; le célibataire invétéré qui a dit ne pas avoir l'âme conjugale ne peut y voir qu'un compromis, une mascarade sociale et religieuse, bref une fraude sentimentale, alors que le vrai mariage suppose une communauté d'âmes («Entre ici ami de mon cœur»). Sur ce sujet, A. Pion établit d'heureux rapprochements avec Rémy de Gourmont et, bien sûr, Simone de Beauvoir qui fait l'éloge de Stendhal en homme qui aime les femmes dans leur vérité, et de la femme stendhalienne qui existe en tant que conscience érotique. Le dernier chapitre, «Stendhal, un théoricien érotique cosmopolite», est le fruit d'une investigation plus personnelle. Une fois rappelés le 
libertin Fabrice, avant sa rencontre avec Clélia, et Gina, incarnation de la virtù (M. Crouzet a vu en elle un "trésor d'énergie érotique», mais ici l'amoureuse absolue paraît négligée), de riches développements sont consacrés aux érotiques provençale et arabe, espèce de contre-épreuve de la réalité occidentale, à propos des chapitres 52 et 53 de De l'Amour. Bien que la connaissance que Stendhal a eue de l'amour courtois et de la «cortezia arabe» ait été indirecte et sans doute idéalisée, A. Pion propose, non sans précautions, un Stendhal proche de l'amour-fou.

4 Un des mérites de ce livre savant et sensible, outre celui d'avoir évité le sujet rebattu de Stendhal et l'amour, est non seulement de corriger erreurs et approximations de la critique stendhalienne, mais plus encore de prouver que Stendhal, qui n'a pas la même conception que les maîtres dont il se réclame, va au-delà des codes traditionnels en proposant une dimension esthétique de l'amour. Contrairement à ce qu'on a pu dire, la théorie passionnelle de Stendhal n'est ni discontinue ni incohérente. De l'Amour est bien un témoignage capital de l'érotique romantique dans lequel Stendhal a dépassé les réformes prudentes des Idéologues en revendiquant les droits de la sexualité féminine, de la passion libre et du plaisir dans l'amour. A. Pion a eu raison de focaliser son attention sur ce texte canonique, véritable plaidoyer en faveur du plaisir d'aimer à l'état pur. 